\title{
High-Resolution Esophageal Manometry in Teenagers with Esophageal Atresia
}

\author{
Cecilia Zubiri ${ }^{1}$, Rosa Ramos ${ }^{2}$, Cecilia Curvale ${ }^{2}$, Raúl Matanó ${ }^{2}$, Roman Bigliardi $^{3}$, Paula Borobia $^{1}$, \\ Anabella Zosi' ${ }^{1}$, Verónica Garrido4, Julieta Hernández4, Lucía Gutierrez5, Luciana Guzmán1, \\ María Cristina Arregui ${ }^{1}$, Marina Prozzi ${ }^{4}$, Sandro Miculan'1, Viviana Bernedo ${ }^{1}$, \\ Maximiliano Fernández Rivas ${ }^{1}$, Cristina Lorenzo ${ }^{1}$, Florencia Recalde', Verónica Valdiviezo ${ }^{1}$, \\ Darío Fajre ${ }^{6}$, Cintia Antonioli ${ }^{7}$, Mariana Allende ${ }^{1}$, Claudia Losada ${ }^{1}$, Teresita Gonzalez ${ }^{1}$ \\ ${ }^{1}$ Department of Gastroenterology at Hospital de Niños Sor María Ludovica, La Plata, Buenos Aires, Argentina \\ ${ }^{2}$ Department of Gastroenterology at Hospital de Alta Complejidad El Cruce, Florencio Varela, Buenos Aires, Argentina \\ ${ }^{3}$ Posadas Hospital, Buenos Aires, Argentina \\ ${ }^{4}$ Department of Nutrition at Hospital de Niños Sor María Ludovica, La Plata, Buenos Aires, Argentina \\ ${ }^{5}$ Department of Surgery at Hospital de Niños Sor María Ludovica, La Plata, Buenos Aires, Argentina \\ ${ }^{6}$ Department of Otorhinolaryngology at Hospital de Niños Sor María Ludovica, La Plata, Buenos Aires, Argentina \\ ${ }^{7}$ Department of Pneumonology at Hospital de Niños Sor María Ludovica, La Plata, Buenos Aires, Argentina \\ Email: cecizubiri03@hotmail.com
}

How to cite this paper: Zubiri, C., Ramos, R., Curvale, C., Bigliardi, R., Matanó, R., Borobia, P., Zosi, A., Garrido, V., Hernández, J., Gutierrez, L., Guzmán, L., Arregui, M.C., Prozzi, M., Miculan, S., Bernedo, V., Rivas, M.F., Lorenzo, C., Recalde, F., Valdiviezo, V., Fajre, D., Antonioli, C., Allende, M., Losada, C. and Gonzalez, T. (2020) High-Resolution Esophageal Manometry in Teenagers with Esophageal Atresia. Open Journal of Epidemiology, 10, 81-89.

https://doi.org/10.4236/ojepi.2020.101007

Received: December 17, 2019

Accepted: February 23, 2020

Published: February 26, 2020

Copyright (c) 2020 by author(s) and Scientific Research Publishing Inc. This work is licensed under the Creative Commons Attribution International License (CC BY 4.0).

http://creativecommons.org/licenses/by/4.0/ (c) (i) Open Access

\begin{abstract}
Introduction: Children with surgically repaired esophageal atresia (EA) show esophageal dysmotility. Due to the performance of high-resolution manometry (HRM), three motility alteration patterns have been described, which allowed to know the segmental alterations. Objective: To describe the esophageal motility patterns found through HRM in teenagers with EA and to relate these with the associated esophageal pathology and its severity. Materials and Method: Ten teenagers were included with no history of esophageal blockage or dilations in the last six months, who were orally fed and asymptomatic. Through performance of HRM, we found surgical and endoscopic history, as well as of esophageal biopsies and $\mathrm{pH}$ monitoring. Results: We found the following patterns: aperistalsis, pressurization and distal contraction. 70\% showed distal contraction, and $100 \%$ of esophageal endoscopies and biopsies were normal. $57 \%$ of the esophageal $\mathrm{pH}$ monitoring analyzed was pathologic. In the pressurization and aperistalsis groups, we observed severe esophagitis and requirement of Nissen antireflux procedure in $100 \%$ of the cases. Esophageal $\mathrm{pH}$ monitoring analyzed was $100 \%$ pathologic. Conclusion: We described the esophageal segmental alterations in teenagers with atresia by means of HRM. The distal contraction group showed better development, without severe esophagitis or requirement of antireflux procedure. Therefore, by performing an HRM in teenagers with EA, we could predict the future
\end{abstract}


esophageal behavior, according to the peristaltic pattern, since there are significant differences among the groups in study.

\section{Keywords}

High-Resolution Manometry, Esophageal Atresia, Teenagers

\section{Introduction}

EA is one of the most frequent birth defects, with an incidence of 1 in 3000 live births [1]. Until the 1950s, these patients had $100 \%$ mortality; nowadays, the survival rate is greater than $90 \%$, and only those with associated severe malformations die [1] [2] [3] [4] [5].

Type C EA (atresia of the esophageal proximal segment with tracheoesophageal fistula between the trachea and the distal segment) is the most common variant, since it is present in $85 \%$ of the cases [6] [7] [8]. There is evidence that the esophageal motor disorder present in these children is secondary to a congenital neuromuscular disorder and a postoperative disorder [9]-[14]. Patients that survive the operation have a greater risk of developing gastroesophageal reflux disease (GERD), caused by anomalies in the esophageal motility and its resulting delay in the evacuation of acid of the esophageal lumen.

There was a hypothesis that suggested that motility alteration could contribute to dysphagia and to the high prevalence of gastroesophageal reflux in these patients [15] [16] [17]. Also, there were reports of a greater incidence of severe esophagitis with requirement of fundoplication, which shows a larger failure rate [16] [17]. Esophageal dysmotility has been proved in children with EA through performance of conventional perfusion manometry.

Lemoine C. et al. described three motility alteration patterns with HRM in children with repaired EA. Said study allowed a more precise knowledge of segmental esophageal motility [18]. Currently, there are no reports exclusively made about teenagers with repaired EA that describe segmental esophageal motility with HRM.

\section{Objective}

To describe esophageal motility patterns found with HRM in teenagers with EA and to relate these with the associated esophageal pathology and its severity.

\section{Materials and Method}

Patients older than 12 years of age with corrected esophageal atresia who were being followed up in the Esophageal Atresia Committee of the Children's Hospital of La Plata, Sr. María Ludovica, Buenos Aires, Argentina, were included in the period between January 2015 and January 2016. Teenagers should be asymptomatic, with no history of esophageal blockage or dilations, during the 
last six months; all feeding orally. With these characteristics, 10 patients were being followed up; five patients were female, and five male. Patients who did not meet age or who were symptomatic with the need for dilation or esophageal blockage in the last six months were excluded.

We collected demographic data (age, sex, birth date), medical history (type of atresia, presence or absence of fistula, associated malformations) and surgical history (postoperative complications, antireflux procedures, esophageal dilations), and reviewed previous studies such as gastrointestinal videoendoscopy and esophageal biopsies, conventional manometry and 24-hour $\mathrm{pH}$ monitoring. The study has been approved by the provincial Ethics Committee.

Being a cross-sectional study, the follow-up of patients was not evaluated in relation to their underlying pathology. There was only intention to know the current status at the time of the study.

HRM Technique

Patients were cited at the El Cruce Hospital in Florencio Varela, Buenos Aires, Argentina, to perform the HREM. The study was performed on an outpatient basis and patients presented with 8 hours of fasting. The procedure was conducted without sedation. The equipment used was a Sandhill Scientific Inc (Rancho, CO, USA) high-resolution manometer, with simultaneous impedance. We used a catheter with 32 pressure sensors/16 impedance sensors, $12 \mathrm{Fr}$.

The procedure started by introducing intranasal xylocaine gel. After 4 - 5 minutes, we nasally introduced the catheter, asking the teenager to take swallows to ease its way to the esophagus. When the right position of the catheter was checked, according to the visual map, we gave them 10 sips of $5 \mathrm{~mL}$ of water to evaluate the motility during liquid deglution. Then, we performed maneuvers to provoque peristaltic strength with multiple liquid (repetitive, $2 \mathrm{~mL}$ each) and solid (pieces of cookies) deglutions. Once the procedure was over, which lasted 15 minutes on average, we withdrawn the catheter and ended the study.

\section{HRM Analysis}

Manometry profiles were analyzed with Bioview ${ }^{\mathrm{TM}}$ (Sandhill ${ }^{\mathrm{TM}}$ ) software (version 5.2.5 [19]) (Rancho, CO, USA). An advanced Gastrointestinal Motility Fellow (MC-KS) analyzed and reviewed all tracings, which were then reassessed by an expert.

The following measures were made: basal pressure of the lower esophageal sphincter (LES) (NV $10-45 \mathrm{mmHg}$ ) and integrated relaxation pressure (IRP), considered normal up to $17 \mathrm{mmHg}$. IRP is determined by pressure values of the gastroesophageal junction during 4 seconds. Then, taking the three thirds of the esophageal body, motility was evaluated, according to the software, as well as the distal contractile integral (DCI, NV: $450-8000 \mathrm{mmHg} / \mathrm{cm} / \mathrm{sec}$ ), in case motility was totally or partially preserved. The contraction front velocity was determined using an isobaric contour line at $30 \mathrm{mmHg}$, in the proximal and distal ends of the distal esophageal segments. In the upper esophageal sphincter (UES), relaxation of the cricopharyngeal, basal pressure of the UES (NV: $30-118 \mathrm{mmHg}$ ), 
pharyngeal coordination and pharyngeal basal pressure (NV: $90-190 \mathrm{mmHg}$ ) were evaluated. The normal values are those determined by the Chicago Classification v3.0 [20]. The swallow was determined by pharyngeal contraction, followed by relaxation of the LES. The contraction of the esophageal body was only considered when deglution generated a pressure greater than $30 \mathrm{mmHg}$, which has been demonstrated to be the minimum pressure needed for a complete bolus transit [21] [22] [23] [24]. LES IRP, tone and residual pressure were also evaluated. DCI was valued and adjusted to the esophageal length, which is considered as the distance between both sphincters.

Results were classified according to the three motility patterns present in children with EA described by Lemoine C. et al. Said patterns were: aperistalsis (without peristaltic wave, with or without LES abnormality), pressurization (simultaneous contraction of the entire esophageal body after deglution in at least 2 swallows) and distal contraction (contraction after deglution in at least 2 swallows in the esophageal middle or distal third) [18].

$\underline{\text { Statistical Analysis }}$

A descriptive analysis was made in a cohort of patients with repaired achalasia.

\section{Results}

Ten teenagers with surgically repaired EA were evaluated. Seven patients were girls. The median age was 15 years (12 - 17 years) and all patients showed adequate growth as for weight and size. $90 \%$ showed type $\mathrm{C}$ atresia and only one of them had type A (EA without fistula). In addition, 50\% of the patients presented associated malformations: syndactyly, sclerosis, mild neurological conditions, cardiopathies or renal diseases. No early postoperative complications were registered. However, $70 \%$ of teenagers presented late postoperative complications, such as stenosis that required dilations. Throughout their lives, $50 \%$ of the patients showed repeated broncho-obstructive features. In previous gastrointestinal videoendoscopies, 3 patients presented esophagitis ( 2 B and one $\mathrm{C}$, according to Los Angeles classification).

When evaluating 24-hour $\mathrm{pH}$ monitoring, we had data of 9 patients with the following results: 3 patients with normal studies (33.3\%). The number of proximal episodes of gastroesophageal reflux and the clearance time of the bolus were within normal values in $100 \%$ of the teenagers.

\section{$\underline{\text { HRM }}$}

Ten studies were performed with no technical difficulties. None of the patients evaluated presented a normal peristaltic pattern and these were classified according to the main peristaltic pattern observed.

We analyzed the tracings and identified 3 different esophageal motility patterns: complete aperistalsis, pressurization and distal esophageal contraction. The complete aperistalsis pattern was present in 2 patients, who showed absence of motility in the esophageal body, with or without LES anomalies. There was 1 teenager with the pressurization pattern, with alteration in the LES relaxation. According to the distal esophageal contraction pattern, we identified 7 patients. 
Table 1. Differences among peristaltic groups according to HRM.

\begin{tabular}{cccc}
\hline & Aperistalsis & Pressurization & Distal Contraction \\
\hline LES pressure & $13 \mathrm{mmHg}$ & $21.5 \mathrm{mmHg}$ & $40 \mathrm{mmHg}$ \\
Normal relaxation & Yes & No & Yes \\
IRP $(<17 \mathrm{mmHg})$ & $12.5 \mathrm{mmHg}$ & $13 \mathrm{mmHg}$ & $12.5 \mathrm{mmHg}$ \\
Proximal amplitude & $6.5 \mathrm{mmHg}$ & $170 \mathrm{mmHg}$ & $23 \mathrm{mmHg}$ \\
Distal amplitude & 0 & $160 \mathrm{mmHg}$ & $41.5 \mathrm{mmHg}$ \\
DCI & 0 & 0 & $281 \mathrm{mmHg} / \mathrm{cm} / \mathrm{sec}$ \\
UES & $111.5 \mathrm{mmHg}$ & $158 \mathrm{mmHg}$ & $63 \mathrm{mmHg}$ \\
\hline
\end{tabular}

HRM, high-resolution manometry; LES, lower esophageal sphincter; IRP, integrated relaxation pressure; DCI, distal contractile integral; UES, upper esophageal sphincter.

Table 2. Requirement for esophageal intervention and its relation to the peristaltic pattern.

\begin{tabular}{lccc}
\hline & Aperistalsis & Pressurization & Distal Contraction \\
\hline Dilation requirement & $50 \%$ & $100 \%$ & $71.5 \%$ \\
Antireflux procedure & $100 \%$ & $100 \%$ & $0 \%$ \\
\hline
\end{tabular}

Pressure of the LES was normal in $90 \%$ of teenagers, with a media of 28.6 $\mathrm{mmHg}$ and a range between 13 and $45 \mathrm{mmHg}$. The other patient presented a pressure of $77 \mathrm{mmHg}$.

Relaxation and IRP were normal in $90 \%$ of the cases. The mean was 11.6 $\mathrm{mmHg}$ and the range between 6 and $17 \mathrm{mmHg}$. There was only one case with increased IRP of $21 \mathrm{mmHg}$, which belonged to the pressurization group.

DCI could only be valued in patients with the distal contraction pattern; these values were below normal in 7 patients and, in 3 of them, a value of 0 $\mathrm{mmHg} / \mathrm{cm} / \mathrm{sec}$. The other 3 patients, with DCI within normal parameters, showed a mean of $565.6 \mathrm{mmHg} / \mathrm{cm} / \mathrm{sec}$, with a range between 464 and $753 \mathrm{mmHg} / \mathrm{cm} / \mathrm{sec}$. In addition, when we observed the UES pressure, the mean value was $86.9 \mathrm{mmHg}$, with a range between 14 and $158 \mathrm{mmHg}$, and 2 cases exceeded the normal value. We also compared the three patterns and described the differences found among them (Table 1 and Table 2).

It should be noted that teenagers that showed the distal contraction pattern had normal results in esophageal endoscopies and its biopsies in $100 \%$ of the cases; however, in the pressurization and complete aperistalsis groups, patients presented severe esophagitis and required Nissen antireflux procedure in 100\% of the cases. Regarding pH monitoring, $100 \%$ of the patients in these 2 groups also had pathologic results, but in the distal contraction pattern group, only $57 \%$ of the cases were pathologic.

\section{Discussion}

As mentioned in the objective of this study, we could describe the esophageal 
segmental alterations in teenagers with atresia through performance of high-resolution manometry and identify the presence of three the peristaltic patterns in pediatric population [25] [26] [27] already described.

Up to now, there are few publications about esophageal motility in patients with EA with HRM [18]-[30] and no studies have been made with a teenage cohort exclusively, age in which it is possible to retrospectively evaluate the evolution of the kid, and to relate him/her with the type of esophageal motility. Singendonk and collaborators compare the Chicago Classification metrics in a pediatric population [28], correlating age, esophageal length and HRM values. Due to the regression analysis, they determined that the patient's age and the shorter esophageal length had positive correlation with a greater IRP, shorter distal latency (DL) and smaller peristaltic break. Mean age was $8.9 \pm 0.7$ years, adjusted for diagnostic criteria. However, in our study, we used adult values, since we had a teenage population with adult size.

In our study, the esophageal motility patterns found in teenagers were identical to those described for the general pediatric population by Lemoine [18]: pressurization, aperistalsis and distal contraction. The differences among the three groups are significant, as regards the presence of GERD and the need for antireflux procedure. We could correlate the type of esophageal motility with the presence or severity of gastroesophageal reflux, but the number of patients is limited, so it is not possible to get a statistical value.

In the pressurization group we only found a patient with incomplete LES relaxation but, since he/she had had Nissen antireflux procedure, we could not determine whether this pattern is present due to a neuromuscular incoordination prior to the fundoplicature or if this is secondary to it. This doubt comes up because we do not have preoperative manometric studies. In the aperistalsis and pressurization groups, $100 \%$ of the patients had had Nissen fundoplicature, while in the distal contraction group, teenagers had never had esophagitis or Nissen fundoplicature. So, we could deduce that in the first two groups, the motor disorder is more severe, conditioning a severe reflux disease. We found no differences regarding symptomatology, according to the peristalsis pattern the patients belonged to, since they were $100 \%$ asymptomatic.

When analyzing 24-hour $\mathrm{pH}$ monitoring, we observed bolus clearance and normal proximal reflux episodes, independently of the motility pattern found. Previous studies of $\mathrm{pH}$ monitoring in patients with EA informed that both parameters are not affected, despite the motor disorder these patients have, and there are no significant differences with the control patients' group [29] [30]. This could partly explain the absence of symptomatology, since clearance has influence on it, as Maheen Hassan refers in her work [31].

\section{Conclusions}

It remains to be established whether, according to the peristalsis pattern presented by the patient, if a prognosis of severity of gastroesophageal reflux disease 
can be estimated.

Taking into account that this population provides little information about symptomatology (due to its chronicity), that there are different motility patterns and that, according to the pattern, severity of the reflux could be different, these patients should be systematically studied and controlled, without waiting for the appearance of symptoms. By performing an HRM combined with $\mathrm{pH}$ monitoring, we can predict the future esophageal behavior and the severity of the gastroesophageal reflux, so we can avoid the performance of multiple unnecessary studies and the presence of greater complications. According to the patient's peristaltic pattern, severity of GERD could be predicted.

Even though our data shows there are significant differences among the evaluated groups, the limited number of cases only allows a descriptive statistical analysis. It is necessary to evaluate a greater number of patients to confirm our hypothesis.

\section{Limitations of the Study}

The size of the probe to perform the HREM was a limitation to select the patients' age. One patient refused to perform the $\mathrm{pH}$-impedance measurement.

\section{Conflicts of Interest}

The authors declare that there are no conflicts of interest in carrying out the work.

\section{References}

[1] Martínez Ferro, M. (2004) Atresia y estenosis del esófago. In: Martínez Ferro, M., Cannizzaro, C., Rodríguez, S. and Rabasa, C., Eds., Neonatología Quirúrgica, Grupo Guía, Buenos Aires, 317-340.

[2] Castilloux, J., Noble, A.J. and Faure, C. (2010) Risk Factors for Short- and Long-Term Morbidity in Children with Esophageal Atresia. The Journal of Pediatrics, 156, 755-760. https://doi.org/10.1016/j.jpeds.2009.11.038

[3] Deurloo, J.A., Ekkelkamp, S., Schoorl, M., Heij, H.A. and Aronson, D.C. (2002) Esophageal Atresia: Historical Evolution of Management and Results in $371 \mathrm{~Pa}-$ tients. The Annals of Thoracic Surgery, 73, 267-272. https://doi.org/10.1016/S0003-4975(01)03263-5

[4] Rokitansky, A.M., Kolankaya, V.A., Seidl, S., et al. (1993) Recent Evaluation of Prognostic Risk Factors in Esophageal Atresia-A Multicenter Review of 223 Cases. European Journal of Pediatric Surgery, 3, 196-201. https://doi.org/10.1055/s-2008-1063542

[5] Goyal, A., Jones, M.O., Couriel, J.M. and Losty, P.D. (2006) Oesophageal Atresia and Tracheo-Esophageal Fistula. Archives of Disease in Childhood: Fetal \& Neonatal, 91, 381-384. https://doi.org/10.1136/adc.2005.086157

[6] Clark, D.C. (1999) Esophageal Atresia and Tracheoesophageal Fistula. American Family Physician, 59, 910-920.

[7] Narasimman, S., Nallusamy, F.R. and Hassan, S. (2013) Review of Oesophageal Atresia and Tracheoesophageal Fistula in Hospital Sultanah Bahiyah, Alor Star. 
Malaysia. From January 2000 to December 2009. Medical Journal of Malaysia, 68, 48-51.

[8] Byun, S.Y., Lim, R.K., Park, K.H., Cho, Y.H. and Kim, H.Y. (2013) Anorectal Malformations Associated with Esophageal Atresia in Neonates. Pediatric Gastroenterology, Hepatology \& Nutrition, 161, 28-33. https://doi.org/10.5223/pghn.2013.16.1.28

[9] Romeo, G., Zuccarello, B., Proietto, F. and Romeo, C. (1987) Disorders of the Esophageal Motor Activity in Atresia of the Esophagus. Journal of Pediatric Surgery, 22, 120-124. https://doi.org/10.1016/S0022-3468(87)80425-6

[10] Pederiva, F., Burgos, E., Francica, I., Zuccarello, B., Martinez, L. and Tovar, J.A. (2008) Intrinsic Esophageal Innervation in Esophageal Atresia without Fistula. Pediatric Surgery International, 24, 95-100.

https://doi.org/10.1007/s00383-007-2032-5

[11] Davies, M.R. (1996) Anatomy of the Extrinsic Motor Nerve Supply to Mobilized Segments of the Oesophagus Disrupted by Dissection during Repair of Oesophageal Atresia with Distal Fistula. British Journal of Surgery, 83, 1268-1270. https://doi.org/10.1002/bjs.1800830929

[12] Shono, T. and Suita, S. (1997) Motility Studies of the Esophagus in a Case of Esophageal Atresia before Primary Anastomosis and in Experimental Models. European Journal of Pediatric Surgery, 7, 138-142. https://doi.org/10.1055/s-2008-1071074

[13] Li, K., Zheng, S., Xiao, X., Wang, Q., Zhou, Y. and Chen, L. (2007) The Structural Characteristics and Expression of Neuropeptides in the Esophagus of Patients with Congenital Esophageal Atresia and Tracheoesophageal Fistula. Journal of Pediatric Surgery, 42, 1433-1438. https://doi.org/10.1016/j.jpedsurg.2007.03.050

[14] Boleken, M., Demirbilek, S., Kirimiloglu, H., Kanmaz, T., Yucesan, S., Celbis, O. and Uzun, I. (2007) Reduced Neuronal Innervation in the Distal End of the Proximal Esophageal Atretic Segment in Cases of Esophageal Atresia with Distal Tracheoesophageal Fistula. World Journal of Surgery, 31, 1512-1517. https://doi.org/10.1007/s00268-007-9070-y

[15] Koivusalo, A., Pakarinen, M.P. and Rintala, R.J. (2007) The Cumulative Incidence of Significant Gastroesophageal Reflux in Patients with Oesophageal Atresia with a Distal Fistula: A Systematic Clinical, pH-Metric, and Endoscopic Follow-Up Study. Clinical Gastroenterology and Hepatology, 42, 370-374. https://doi.org/10.1016/j.jpedsurg.2006.10.010

[16] Sistonen, S.J., Koivusalo, A., Nieminen, U., et al. (2010) Esophageal Morbidity and Function in Adult with Repaired Esophageal Atresia with Tracheoesophageal Fistula: A Population-Based Long-Term Follow-Up. The American Surgeon, 251, 1167-1173. https://doi.org/10.1097/SLA.0b013e3181c9b613

[17] Taylor, A.C., Breen, K.J., Auldist, A., et al. (2007) Gastroesophageal Reflux and Related Pathology in Adults Who Were Born with Esophageal Atresia: A Long-Term Follow up Study. Clinical Gastroenterology and Hepatology, 5, 702-706. https://doi.org/10.1016/j.cgh.2007.03.012

[18] Lemoine, C., Aspirot, A., Le Henaff, G., Piloquet, H., Lévesque, D. and Faure, C. (2013) Characterization of Esophageal Motility Following Esophageal Atresia Repair Using High-Resolution Esophageal Manometry. JPGN, 56, 609-614. https://doi.org/10.1097/MPG.0b013e3182868773

[19] Do Carmo, G.C., Jafari, J., Sifrim, D. and De Oliviera, R.B. (2015) Normal Esophageal Pressure Topography Metrics for Data Derived from the Sandhill-Unisensor 
High-Resolution Manometry Assembly in Supine and Sitting Positions. Neurogastroenterology Motility, 27, 285-292. https://doi.org/10.1111/nmo.12501

[20] Kahrilas, P.J., Bredenoord, A.J., Fox, M., Gyawali, C.P., Roman, S., Smout, A.J. and Pandolfino, J.E. (2015) The Chicago Classification of Esophageal Motility Disorders, V3.0. Neurogastroenterology Motility, 27, 160-174. https://doi.org/10.1111/nmo.12477

[21] Pandolfino, J.E., Ghosh, S.K., Rice, J., Clarke, J.O., Kwiatek, M.A. and Kahrilas, P.J. (2008) Classifying Esophageal Motility by Pressure Topography Characteristics: A Study of 400 Patients and 75 Controls. American Journal of Gastroenterology, 103, 27-37. https://doi.org/10.1111/j.1572-0241.2007.01532.x

[22] Kahrilas, P.J., Ghosh, S.K. and Pandolfino, J.E. (2008) Esophageal Motility Disorders in Terms of Pressure Topography: The Chicago Classification. Journal of Clinical Gastroenterology, 42, 627. https://doi.org/10.1097/MCG.0b013e31815ea291

[23] Bredenoord, A.J., Fox, M., Kahrilas, P.J., Pandolfino, J.E., Schwizer, W. and Smout, A.J. (2012) Chicago Classification Criteria of Esophageal Motility Disorder Defined in High Resolution Esophageal Pressure Topography. Neurogastroenterology \& Motility, 24, 57-65. https://doi.org/10.1111/j.1365-2982.2011.01834.x

[24] Goldani, H.A., Staiano, A., Borrelli, O., Thapar, N. and Lindley, K.J. (2009) Pediatric Esophageal High-Resolution Manometry: Utility of a Standardized Protocol and Size-Adjusted Pressure Topography Parameters. American Journal of Gastroenterology, 105, 460-467. https://doi.org/10.1038/ajg.2009.656

[25] Pandolfino, J.E., Fox, M.R., Bredenoor, A.J. and Kahrilas, P.J. (2009) High-Resolution Manometry: In Clinical Practice: Utilizing Pressure Topography to Classify Oesophageal Motility Abnormalities. Neurogastroenterology \& Motility, 21, 796-806. https://doi.org/10.1111/j.1365-2982.2009.01311.x

[26] Staiano, A., Boccia, G., Miele, E. and Clouse, R.E. (2008) Segmental Characteristics of Esophageal Peristalsis in Pediatric Patients. Neurogastroenterology \& Motility, 20, 19-26.

[27] Staiano, A., Boccia, G., Salvia, G., Zappulli, D. and Clouse, R.E. (2007) Development of Esophageal Peristalsis in Preterm and Term Neonates. Gastroenterology, 132, 1717-1725. https://doi.org/10.1053/j.gastro.2007.03.042

[28] Singendonk, M., Kritas, S., Cock, C., et al. (2014) Applying the Chicago Classification Criteria of Esophageal Motility to a Pediatric Cohort: Effects of Patient Age and Size. Neurogastroenterology \& Motility, 26, 1333-1341. https://doi.org/10.1111/nmo.12397

[29] Van Wijk, M., Knüppe, F., Omari, T., de Jong, J. and Benninga, M. (2013) Evaluation of Gastroesophageal Function and Mechanisms Underlying Gastroesophageal Reflux in Infants and Adults Born with Esophageal Atresia. Journal of Pediatric Surgery, 48, 2496-2505. https://doi.org/10.1016/j.jpedsurg.2013.07.024

[30] Tong, S., Mallitt, K.A. and Krishnan, U. (2016) Evaluation of Gastroesophageal Reflux by Combined Multichannel Intraluminal Impedance and $\mathrm{pH}$ Monitoring and Esophageal Motility Patterns in Children with Esophageal Atresia. European Journal of Pediatric Surgery, 26, 322-331. https://doi.org/10.1055/s-0035-1564715

[31] Hassan, M. and Mousa, H. (2017) Impedance Testing in Esophageal Atresia Patients. Frontiers in Pediatrics, 5, 85. https://doi.org/10.3389/fped.2017.00085 